\title{
Fascia and tensegrity: The quintessence of a unified systems conception
}

\author{
John Sharkey.
}

Faculty of Medicine, Dentistry and Clinical Sciences, University of Chester/NTC,15-16aSt Joseph's Parade, Dorset St, DO7 FR6C, Dublin, Ireland.

\section{ABSTRACT}

The heterogeneous connective tissue fascia is constructed upon a tensegrity-based architecture providing cells and organism's with stability coupled with mobility. A term coined by Sharkey and Avison "Fasciategrity"used for the first time at the British Fascia Symposium 2018, speaks of the relationship of balance and integrity within the fascial net. Tensegrity construction principles provide an opportunity to deliver, to medical trainees and postgraduate medical specialists, a unified systems conception of living form and function. In this the $21^{\text {st }}$ century anatomists are ready to move away from a mechanical view of the human corpus based on a $17^{\text {th }}$ century model of parts and levers. A new emphasis is required to integrate current models and theories that substantiatefascia as the connected, unifying, continuous universal singularity that permeates the entire soma. Such models and theories are complex, however, with increased crosstalk between experts and professionals in fields of specialty, within scientific disciplines, a new paradigm is emerging. This new unified systems approach to human anatomy and physiology has the potential to impact global healthcare.A unified systems model of human anatomy (with a special focus on the architecture of fascia) is one that is predicated upon a specific 'nature inspired' tensegrity architecture utilizing soft matter as the building materialduringembryonic self-construction. Self-construction leads to emerging transformations that are driven by both genetic and epigenetic stresses [i.e., biochemical and biophysicalcues] embracing collective behaviour with emerging small world networks that utilize non-linear dynamics. Time is a key component as self-organization occurs in a hierarchical time-dependent/temporal sequalae. This short paper focuses on the essential architectural characteristics of cells and multi-cellular organismsthat supports a living unified system. While the human body is a true reflection of infinity and continuity it also possesses virtual boarders, boundaries and compartmentalization's. Such virtual borders and boundaries are self-constructed connections, disconnections and compartments necessary for physiology, metabolism and autoimmune responsesreflecting evolutionary contingency.

KEY WORDS: Fascia, Tensegrity, Continuity, Unified Systems, Biotensegrity, Stability, Embryology.

Corresponding Author: John Sharkey MSc, Faculty of Medicine, Dentistry and Clinical Sciences, University of Chester/NTC, 15-16aSt Joseph's Parade, Dorset St, DO7 FR6C, Dublin, Ireland. E-Mail: john.sharkey@ntc.ie

Access this Article online

Quick Response code

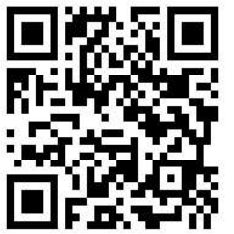

DOI: $10.16965 /$ ijar.2020.751

Journal Information

International Journal of Anatomy and Research

ISSN (E) 2321-4287 | ISSN (P) 2321-8967

https://www.ijmhr.org/ijar.htm

DOI-Prefix: https://dx.doi.org/10.16965/ijar

Article Information

Received: 22 Dec 2020

Peer Review: 23 Dec 2020

Revised: None
Accepted: 27 Jan 2021

Published (O): 20 Feb 2021

Published (P): 05 Mar 2021

\section{INTRODUCTION}

Embedded in the philosophy of human biomechanics is man as machine [1]. The erroneous nature of man as machine is self-evident. Machines are man-made. Living constructs are self-developed, self-constructed, self-emerging, self-stressed, unified systems maintaining constancy through an ever-changing internal environment providing allostatic balance [2]. Machines are constructed from hard matter constituents which are Hookean materials following Hooke's law, therefore, reflecting the fallacy of biomechanics $[3,4]$.

Living constructs are composed of soft matter 
material that naturally express non-linear behaviour [i.e., non-linear stress/strain curves] and therefore have no valid Young's modulus or Poison's ratio [4]. Recent research [5, 6] has confirmed what some experts viewed as a surprising mechanical characteristic in human and animal tendons known as auxeticity whereby tissue does not shrink but rather expands transverse to the direction of extension when stretched. Auxeticity and thixotropy are characteristics expressed in the physical properties of soft matter [5]. For example, Francisco Torrent-Guasp's anatomical dissection revealinga helical heart, a result of spiral folding [Fig $1 \mathrm{a}$ and $\mathrm{b}$ ], has brought to a reasonable conclusion, the elusive ambitions of Erasistratus, Leonardo da Vinci, Galen and other great pantheons of anatomy who, having attempted to unravel the heart, could not reveal its true helical nature[7].
Erasistratus and Galen were among the first to note that blood was sucked into the heart when filling [i.e., diastole] and that the heart muscle got wider, reflecting the auxetic and tensegral nature of the myocardium, during the contraction phase [i.e., systole] [7]. Any disagreement among anatomists and cardiologists concerning the accuracy of the helical ventricular myocardial band (HVMB) would benefit with the inclusion of tensegrity architectural principles and the concept of living tissue as soft matter containing liquid crystals [3]. All liquid crystals operate on a spectrum of hardness to softness, without straying from their fundamental category of soft matter. All liquid in the human body (with the exception of urine) is bound. Bones begin as cartilaginous placeholders and "crystalize" into harder cases, containing soft matter within their more crystalline arrangements [9].

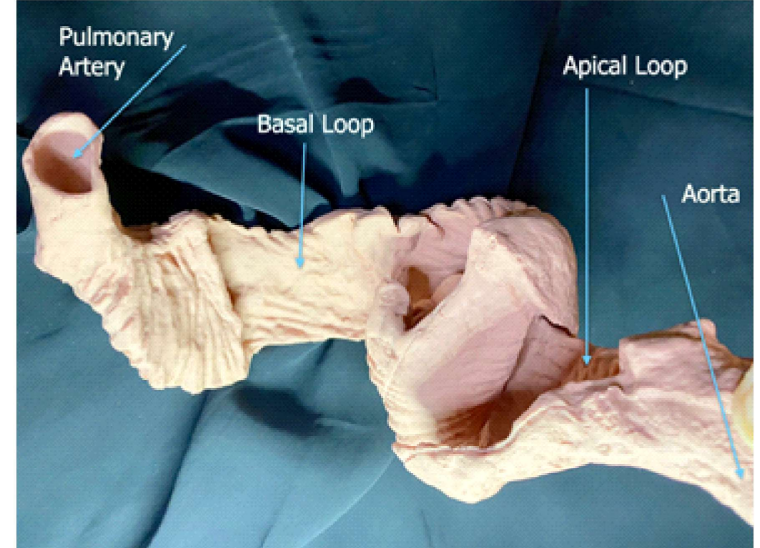

a

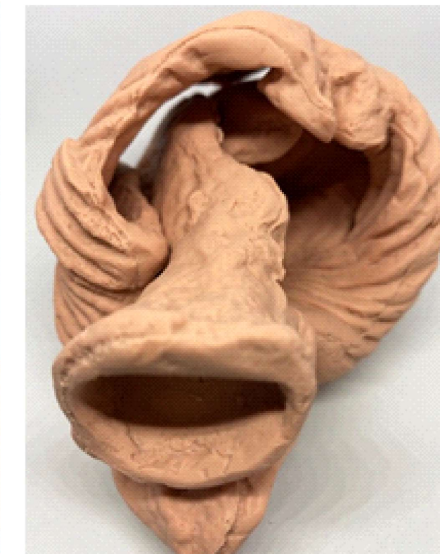

b

Figure 1 a and b: Torrent Guasp Band. The biventricular myocardial band. Images: Sharkey, J 2020. Francisco Torrent-Guasp's anatomical dissection revealing the helical ventricular myocardial band (HVMB), a result of spiral folding, bringing to a reasonable conclusion, the elusive ambitions of Erasistratus, Leonardo da Vinci, Galen and other great pantheons of anatomy who, having attempted to unravel the heart, could not reveal its true helical nature, a feat deserving the noble prize.

Tensegrity- the model of cellular architectureand force transfer: Tensegrity is a compression of the words, tension and integrity, a term created by designer, inventor and futurist $R$. Buckminster Fuller. It is not a true noun but an invented word/term to help explain a model of living architecture [3]. "My tensegrity" and "Islands of compression inside an ocean of tension" are descriptions Fuller used as part of a patent submission Fuller made in 1962 [10]. Fuller also referred to "tensional integrity" while renowned contemporary sculptor and photographer Kenneth Snelson preferred to define tensegrity as "floating compression" [10]. Human beings follow the same rules of softmatter physics as do all living organisms in a vast variety of morphological expressions. The laws governing tensegrity have been established as applying to the organism, thus, they alsoapply to fascia and the extra-cellular matrix at all developmental stages of embryology [31]. While physical laws concerning forces and force transmission do not change, the nature of the self-developmental forming processes go through variations [12]

Due to the singular nature of fascia, proposals have been previously put forward, with 
supporting evidence, arguing that bone is fascia and therefore a change in the taxonomy of bone has been proposed [8, 9]. The microscopic left and right-handed epithelium, the helically constructed collagen of blood vessels with the spiral configurations contained within the myocardium, contain a tensegrity architecture which is the basis of form for all fascial structures [10]. A tensegrity structure comprises pre-stressed elements balanced between tensional and compressional members resulting in emergent propertiesranging from rigidity to mobility with stability, otherwise known as "pre-stress stability" or "super stability"[11]. Evidence that tensegrity expressed cellular architecture [i.e., biotensegrity] provides the vital pre-stress required for cellular shape integrity, physiology and metabolism, by means of molecular microfilaments and microtubules, was established as early as 1983 [12].

As a pre-stressed tensegrity structure,cells dissipate local stresses translating forces on a local and global basis via mechanical exchanges through integrins and other transmembranous molecules [13].

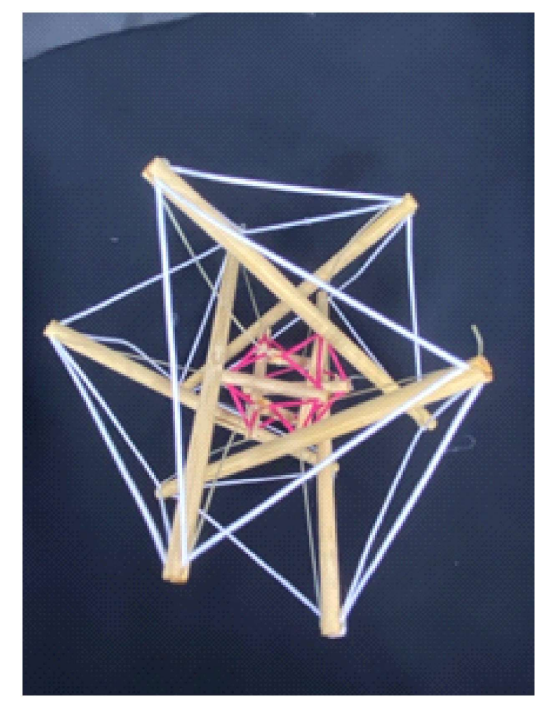

Fig.2: The human body is organized in nested tensegrity networks formed micro to macro and constructed of systems within systems. This image shows a tensegrity nested within a tensegrity as a visual representation of an architecture that is scale free. Image: Sharkey, J. 2020.

The human body is organized in nested tensegrity networks [Fig 2] formed micro to macro and constructed of systems within systems [14].All constituent proteins, fats and carbohydrates [i.e., proteoglycans, muscle fibers, lipid membranes] constituting bone, myofascia, blood vessels and nerves are tensegrity based, inhomogeneous, anisotropic structures at all scale sizes [15]. Biotensegrity is a model of the binding geometries by which forces transmit through all aspects of all living soft-matter forms and cannot be selectively applied to certain stages of the form, or to certain items within that form. In its fullest expression biotensegrity is a model of wholeness with the tensegrity-icosahedron being the basic form that acts invariably as a liquid crystal due to the geometric constraints of close packing in living volumetric forms [10].

No other platonic volumes can demonstrate these attributes and exhibit phase-change throughout the matrix as an expression of life [10]. Researcher Donald Ingber has described tensegrity as a model for explaining how mechanical forces regulate cellular activity [15].

As a living tensegrity construct this architectural blueprint uniquely includes 'selfgenerated stress' utilized at all scales and in all tissues including bone, myocardial tissue, liver, spleenand nerve [16]. Levin has described how bones and myofascial structures, from the micro to the macro level, act as tensegrities providing balance and stability in a closed multi-bar kinematic system [17].

Cellular tensegrity architecture, comprised ofbiopolymers, including active contractile cytoskeletal microfilaments and passive osmotic elements combine to convert interconnected mechanical forces via the extracellular matrix and cytoskeletal networks into biochemical physiology, metabolism and motion [18]. Tensegrity thus provides a model dependent reality of continuity [Fig 3] from the cellular and intracellular ranks to the higher ranking of a unified system [i.e., organism]. Myofascial force transmission, including involvement of septa, tendons and ligaments, all tensegrity-based structures, function as mechanosensitive signaling networks on a body-wide basis [19-22]. These structures have been identified as important site-specific fascia tuning pegs providing appropriate tuning specific tension necessary for the integrity of the fascial net [i.e., Fasciategrity] [23]. 


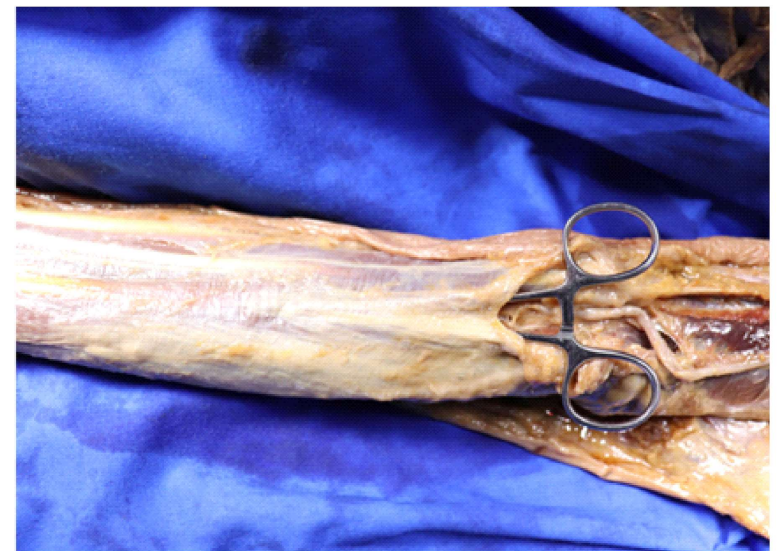

Fig. 3: Tensegrity provides a model dependent reality of continuity from the cellular and intracellular ranks to the higher ranking of a unified system [i.e., organism]. Myofascial force transmission, involving septa, tendons and ligaments, all tensegrity-based structures, function as mechanosensitive signaling networks on a body-wide basis. In this image the haemostat is placed beneath the anti-brachial fascia to highlight the continuity of the fascial net. Image: Sharkey, J 2019.

Contra-argumentshave been madeconcerning the risks of biotechnologies used in agriculture due to a lack of understanding concerning cellular dynamics [24]. Such research is an example of information from disparate fields of specialty, yet allied scientific disciplines, that can inform discussion in anatomy and medicine. Altieri'sfindings highlight alack of understanding concerning genetic function without appreciating that cells operate in acollaborative synergistic co-operative within cellular networks, a first principle of living tensegrity [24].

This takes us in an opposite direction from the currently accepted model [i.e., biomechanics] whereby the whole is equal to the sum of its parts representing a bottom-up approach for explaining complexity [25]. Patterns of genetic activity change moment to moment in response to the intra and extracellular matrix in which they are entrenched [30]. Organisms are constituted from many specialized interacting components that lead to enhanced complexity and greater integration [26, 30].

Complexity generatesunexpected emergent properties demonstrating thatcomplex unified systems are more than the sum of their parts and represent a wholistic top-down approach and a model of 'form follows force' [26, 27]. According to research from Stopak and Harris [Fig 4] undifferentiated extracellular matrix assembles itself, dependent on the stresses acting upon it, resulting in bone, cartilage, blood vessels, muscle fibers, lymphatic tissue and other [28]. Discussion regarding force transfer focuses our attention on the local and global model of mechanotransduction whereby cells respond to forces and translate such stressors to cue physiological, metabolic, and movement responses $[29,30]$.

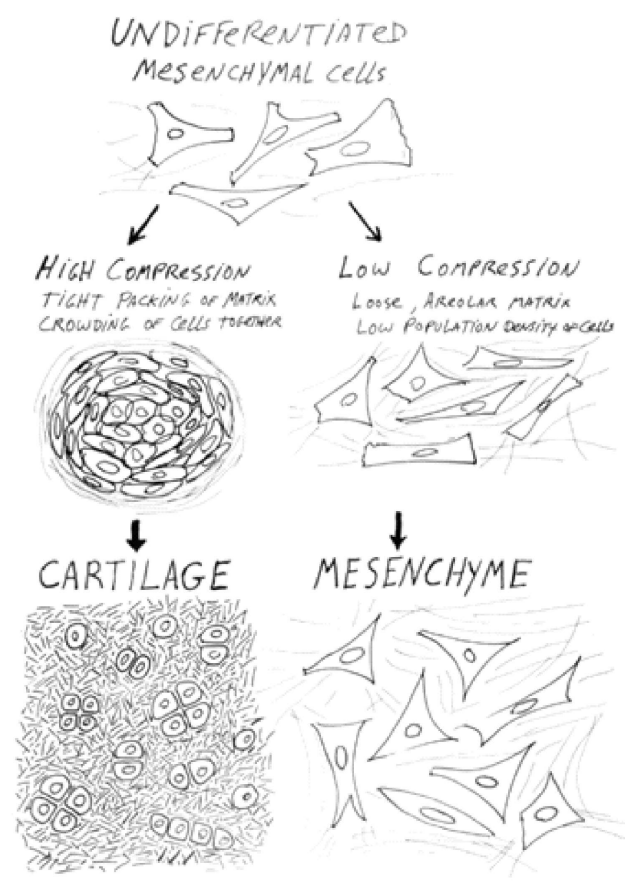

Fig. 4: Undifferentiated extracellular matrix constructs itself dependent on the forces acting upon it.

The scientific evidence cited in this article points to a body that is connected from the innermost intra-cellular matrices via the cytoskeleton to the outermost unified somatic systems reflecting increasing complexity[31]. A focus on chemical cues as a result of combining forces may hold the key to the vision of human embryology, differentiation, growth, topography, anatomy, physiology and behaviour [32]. This points to a reality whereby the very nature of biochemical activity has a physicality at the heart of molecular gene expression influenced by environmental and various anthropological influences [33]. At the heart of this physicality lies tensegrity icosahedron based architecture, present on a ubiquitous scale, via the extracellular matrix required for force generation and translation [12].

Oscillatory contributions to living kinematics: The word biomechanics is clear in its intension to describe the combined inner workings 
that result in living motion as a result of movement around a fixed axis. Bio, referring to living constructs and mechanics or mechanical, from the Greek 'mçchanikç', meaning to study the mechanical theories and principles of living organisms [3]. Mechanical constructs require a screw or pin to stabilize and fixate separate components to supportoperation as a whole and therefore falls short of a satisfactory explanation for human movement [3]. Nature has had the required time to work out the most ephemeral way, combined with self-emergence via self-development, to provide a continuous anatomy, unbroken and uninterrupted, necessary for energy efficient motion [3]. Inappropriate oscillations, a result of strong winds, created a sway that destroyed the Tacoma Narrows Bridge in 1940. Every human cell oscillates at its own specific frequency ensuring differentiation and healthy physiology [34]. Embryologically, motion occurs before consciousness, and it is believed that movement may be the precursor to, and generator of, consciousness based on frequency specific oscillations/resonance [35]. A centrally originating oscillation/resonance in the $10 \mathrm{~Hz}$ range has been shown to modulate slow digital movements and pre-emptive smooth eye movements [36]. The human construct avails of nested tensegrities providing non-linear, synchronous, frequency specific resonant oscillations [Fig2]. Such oscillations are translated via mechanotransduction into metabolism and nutritious or detrimental motion, or undesired vibration, similar to the events at Tacoma Narrows Bridge [37]. Rather than a system of parts, a system of continuity and connectedness with appropriate frequency specific resonance is the proposed vision of anatomy in this the $21^{\text {st }}$ century [3].

\section{CONCLUSION}

The teaching of anatomy by dissection is regarded, by many medical students and post-graduate medical professionals, as the most effective way to learn anatomy. Clinical relevance is critical to the practicing surgeon, general medical practitioners and other specialists. The topic of fascia is scarcely included within the medical anatomy curriculum and one would be hard pushed to find even a paragraph devoted to fascia in any anatomy or embryology textbook. Increased interest in fascia research undeniably attests to the ubiquitous nature of fascia while embryology provides a rich hunting ground for bloodless plains essential during surgery to ensure minimally invasive disruption and subsequent scarring.

The tensegrity model provides a modern alternative to the current biomechanics of one muscle one action, origins and insertions, offering a new vision of living constructs as self-developed, self-constructed, self-emerging, self-stressed, unified systems maintaining constancy through an ever-changing internal environment providing allostatic balance. The tensegrity model encourages a move away from a "musculoskeletal system" whereby muscles "hang off" or are "attached to" bone and moves us towards a unified systems, continuous, soft matter construct that naturally expresses non-linear behaviour and where disruption to one location can impact locally and globally. It is hoped that this paper will encourage interest and discussion among members of various anatomical societies and medical educational authorities to consider the inclusion of tensegrity in the medical curriculum while broadening the topic of fascia and its clinical relevance. The combining of fascia science and tensegrity principles has been promoted as "Fasciategrity", a useful term in helping learners appreciate the inter-dependency of fascia and tensegrity.

\section{Conflicts of Interests: None}

\section{REFERENCES}

[1]. Marcum, J. A. Biomechanical and phenomenological models of the body, the meaning of illness and quality of care. Med Health Care Philos. 2004;7(3):311-20. doi: 10.1007/s11019-0049033-0. PMID: 15679023.

[2]. Ramsay, D. S., \& Woods, S. C. Clarifying the roles of homeostasis and allostasis in physiological regulation. Psychological review, 2014;121(2):225247. https://doi.org/10.1037/a0035942

[3]. Sharkey, J. Biotensegrity-Fascia and the fallacy of biomechanics. Parts 1,2,3. 2018. AAMT Journal.

[4]. Sharkey, J. Re: Transmission of muscle force to fascia during exercise. Thomas Findley, M.D, Ph.D, 
Hans Chaudhry, Ph.D, Sunil Dhar, Ph.D. 2015. Journal of Bodywork \& Movement Therapies:2015;19:119-123.

[5]. Gatt, R., VellaWood, M. et al.Negative Poisson's ratios in tendons: an unexpected mechanical response. Acta Biomater.2015;24:201-208. 10.1016/ j.actbio.2015.06.018

[6]. Firminger, R. Colin., Edwards, W. Brent. A biomechanical study of clamping technique on patellar tendon surface strain and material properties using digital image correlation. 2021. Journal of the Mechanical Behaviour of Biomedical Materials. 2021;113:January, 104156

[7]. Torrent-Guasp, F., Buckberg, G. D., Clemente, C., Cox, J. L., Coghlan, H. C., Gharib, M. The structure and function of the helical heart and its buttress wrapping. I. The normal macroscopic structure of the heart. 2001. Semin Thorac Cardiovasc Surg.2001;Oct;13(4):301-19. doi: 10.1053/ stcs.2001.29953. PMID: 11807730.

[8]. Sharkey J. Regarding: Update on fascial nomenclature-an additional proposal by John Sharkey MSc, Clinical Anatomist. Journal of Bodywork and Movement Therapies. 2019 Jan;23[1]:6-8. DOI: 10.1016/ j.jbmt.2018.11.006.

[9]. Sharkey, J. Should bone be considered fascia? Proposal for a change in taxonomy of bone- a clinical anatomist's view. International Journal of Biological and Pharmaceutical Sciences Archive, 2020;01(01):001-010.

[10]. Sharkey J. Biotensegrity- The Structure of Life. Chapter 8, Pages 99-113. 2020 in: Fascia, Function and Medical Applications. Edited by Lesondak, D., Akey, M, A. CRC Press, Taylor and Francis Group.

[11].Connelly R. Tensegrity Structures: Why are They Stable? In: Thorpe M.F., Duxbury P.M. (eds) Rigidity Theory and Applications. 2002. Fundamental Materials Research. Springer, Boston, MA. https:/ /doi.org/10.1007/0-306-47089-6_3

[12]. Ingber, D. Cellular tensegrity: defining new rules of biological design that govern the cytoskeleton. J. Cell Sci.1993;104:613-627.

[13]. Wang, N., Ingber, D. Probing transmembrane mechanical coupling and cytomechanics using magnetic twisting cytometry. Biochem. Cell Biol.1995;73:1-9.

[14].Chen, C.S., Ingber, D. Tensegrity and mechanoregulation: from skeleton to cytoskeleton. Osteoarthritis Cartilage.1999;7:81-94.

[15]. Ingber, D.Tensegrity: the architectural basis of cellular mechanotransduction. Annual Review of Physiology. 1997;59:575-599. DOI: 10.1146/ annurev.physiol.59.1.575.

[16]. Zhang, J.Y., Ohsaki, M., Kanno, Y. A direct approach to design of geometry and forces of tensegrity systems. Int. J. Solids Struct., 2006;43:2260-2278.

[17]. Levin, S, M. A different approach to the mechanics of the human pelvis: tensegrity. 1997. In: Vleeming, A., Mooney, V., Dorman, T., Snijders, C., Stoeckart, R. Eds. Movement, Stability and Low Back Pain. London: Churchill Livingston:157-67.
[18]. Ingber, D. Opposing views on tensegrity as a structural framework for understanding cell mechanics. J Appl Physiol 2000 Oct;89[4]:1663-70. doi:10.1152/jappl. 2000.89 .4 .1663 . PMID: 11007610.

[19]. Maas, H., Huijing, P. A. Myofascial force transmission in dynamic muscle conditions: effects of dynamic shortening of a single head of multitendoned rat extensor digitorum longus muscle.Eur J Appl Physiol. 2005 Aug; 94(5-6):584-92.

[20]. Huijing, P. A., Langevin, H. M. Communicating about Fascia: history, pitfalls and recommendations. In: Huijing PA, Hollander P, Findley TW, Schleip R (eds) Fascia research II. Basic science and implications for conventional and complementary health care. Elsevier/Urban \& Fischer, München, pp 316-320 Also in: 2009 International Journal of Therapy, Massage and bodywork 2: 3-8.

[21]. Yucesoy, C, A. Epimuscular myofascial force transmission implies novel principles for muscular mechanics. Exerc Sport Sci Rev 2010;38:128-134.

[22]. Huijing, P. A. Epimuscular myofascial force transmission: a historical review and implications for new research. International Society of Biomechanics Muybridge award lecture, Taipei. J Biomech2009;42:9-21.

[23]. Sharkey, J. Site specific fascia tuning pegs and places of perilous passage. Myofascial considerations in upper extremity entrapment neuropathies-A Clinical Anatomists view. International Journal of Anatomy and Research, Int J Anat Res 2020;8(4.2):7823-28. ISSN 2321-4287 DOI: https:/ /dx.doi.org/10.16965/ijar.2020.237

[24]. Altieri, M., Rosset, P.Ten reasons why biotechnology will not ensure food security, protect the environment and reduce poverty in the developing world. Agbioforum, 1998;2:3-4.

[25]. Pezzulo, G., Levin,M,. Top-down models in biology: explanation and control of complex living systems above the molecular level. J R Soc Interface. 2016;13(124):20160555. doi:10.1098/ rsif.2016.0555

[26]. Kane, A, Emily., Higham, E. Timothy. Complex Systems Are More than the Sum of Their Parts: Using Integration to Understand Performance, Biomechanics, and Diversity. 2015. Integrative and Comparative Biology, 2015;55(1):146-165. https://doi.org/10.1093/icb/icv033.

[27]. Veenendaal, D., Block, P. An overview and comparison of structural form finding methods for general networks. 2012. Int J Solids Struct 2012;49:37413753.

[28]. Harris, A.K., Wild, P., Stopak, D. Silicone rubber substrata: A new wrinkle in the study of cell locomotion. Science1980;208:177-179.

[29].Paluch, E. K., Nelson, C. M., Biais, N., Fabry, B., Moeller, J., Pruitt, B. L., Wollnik, C., Kudryasheva, G., Rehfeldt, F., \&Federle, W. Mechanotransduction: use the force(s). BMC biology, 2015;13:47. https:/ /doi.org/10.1186/s12915-015-0150-4 
[30]. Avison, J. Yoga, Anatomy, Fascia and Motion 2nd Ed. 2020. Handspring Publishing, Scotland.

[31]. Ingber, D. Tensegrity II. How structural networks influence cellular information processing networks. Journal of Cell Science2003;116:1397-1408; doi: $10.1242 / j c s .00360$

[32]. Gendle, Mathew, H. "The Problem of Dualism in Modern Western Medicine." Menssana monographs 2016;14(1):141-151. doi:10.4103/09731229.193074

[33]. Mehta, A. D., Rief, M., Spudich, J. A., Smith, D. A. and Simmons, R. M. Single-molecule biomechanics with optical methods. Science 1999;283:16891695.

[34]. Muehsam, D., Ventura, C. Life rhythm as a symphony of oscillatory patterns: electromagnetic energy and sound vibration modulates gene expression for biological signaling and healing. 2014. Glob Adv Health Med. Mar;3(2):40-55. doi: 10.7453/ gahmj.2014.008. PMID: 24808981.
[35]. Cebolla, Ana Marie., Cheron, Guy. Understanding Neural Oscillations in the Human Brain: From Movement to Consciousness and Vice Versa. 2019. Front. Psychol., 27th August. https://doi.org/ 10.3389/fpsyg.2019.01930

[36]. McAuley, J. H., Farmer, S. F., Rothwell, J. C., \& Marsden, C. D. Common 3 and $10 \mathrm{~Hz}$ oscillations modulate human eye and finger movements while they simultaneously track a visual target. 1999. The Journal of physiology, 1999;515(Pt 3):905-917. ht t p s://doi.org/10.1111/j.14697793.1999.905ab.x

[37]. Caluwaerts, Ken., Carbajal, Juan Pablo. Energy conserving constant shape optimization of tensegrity structures. 2015. International Journal of Solids and Structures, 2015;58:117-127 Sharkey, J. 2018. Biotensegrity focused Thiel soft fixed cadaver full body dissection courses.

How to cite this article:

John Sharkey. Fascia and tensegrity: The quintessence of a unified systems conception. Int J Anat Res 2021;9(1.2):7874-7880. DOI: 10.16965/ijar.2020.251 